\title{
Incorporating Diegetic Elements to Increase Engagement in Games for Engi- neering Education
}

\section{Ms. Katherine Smith, Old Dominion University}

Katherine Smith received B.S. degrees in applied mathematics and mechanical engineering from Old Dominion University and an M.S. in Applied and Computational Mathematics from Old Dominion University. Ms. Smith is currently a senior lecturer in the Department of Mathematics and Statistics at Old Dominion University and is pursuing a $\mathrm{PhD}$ in Modeling and Simulation. Her research interests include serious games for STEM education, scientific visualization, and augmented and virtual reality. Prior to teaching at ODU, she worked as an Aerospace Engineer at NASA Langley Research Center.

\section{Prof. Yuzhong Shen, Old Dominion University}

Yuzhong Shen received his B.S. degree in Electrical Engineering from Fudan University, Shanghai, China, M.S. degree in Computer Engineering from Mississippi State University, Starkville, Mississippi, and $\mathrm{Ph} . D$. degree in Electrical Engineering from the University of Delaware, Newark, Delaware. His research interests include computer graphics, visualization, serious games, signal and image processing, and modeling and simulation. Dr. Shen is currently an Associate Professor of the Department of Modeling, Simulation, and Visualization Engineering and the Department of Electrical and Computer Engineering of Old Dominion University. He is also affiliated with Virginia Modeling, Analysis, and Simulation Center (VMASC). Dr. Shen is a Senior Member of IEEE.

\section{Dr. Anthony W. Dean, Old Dominion University}

Dr. Anthony W. Dean has had several roles in academia. He is currently Assistant Dean for Research, Batten College of Engineering and Technology (BCET) at ODU. His previous appointments include Associate Professor of Engineering Technology and as Associate Director of the Institute for Ship Repair, Maintenance, and Operations at Old Dominion University (ODU).His research has focused mostly on control systems (integration and testing) and the reliability and maintainability of complex systems. He has been selected as both a NASA and an ONR Faculty Fellow. He regularly teaches courses in Marine Engineering and in Maintained Systems. Most recently Dr. Dean was on the Headquarters Staff the American Society of Naval Engineers. He received his Ph.D. from the Department of Engineering Management and Systems Engineering, and a B.S. in Nuclear Engineering Technology, from the Batten College of Engineering and Technology at Old Dominion University. Additionally, Dr. Dean received an MBA from the College of William and Mary. Prior to is academic career Dr. Dean was Director of Operations and Business Development for Clark-Smith Associates, P.C., and served as an Electrician in the US Navy aboard the USS South Carolina and the USS Enterprise. 


\title{
Incorporating Diegetic Elements to Increase Engagement in Games for Engineering Education
}

\begin{abstract}
One of the difficulties in developing educational games is maintaining player engagement. This engagement is critical for games to provide effective learning experiences. One way to increase engagement in games is to limit interruptions during game play. In educational games, this can be accomplished by incorporating learning or problem-solving elements diegetically. Diegetic elements are those that are part of the game scene. With this in mind, a series of games for Science, Technology, Engineering, and Mathematics (STEM) education has been developed focusing on content in courses that are prerequisites to the engineering curriculum. These games cover topics in pre-calculus, calculus, physics, and chemistry and incorporate learning elements diegetically. This paper will focus on techniques for implementing learning components as diegetic elements in games to increase player engagement. Additionally, concrete examples will be provided to further elucidate these techniques.
\end{abstract}

\section{Introduction}

Maintaining engagement in educational games is a difficult task. Ideally, players would remain engaged in play throughout the game and not perceive transitions from play to practice, or learning, and back again. Since it is important that educational games are content-focused, it becomes the responsibility of the game developer to seamlessly transition between features associated with play and those associated with learning. One technique for doing this is to incorporate the learning elements into the game as diegetic elements. Diegetic elements are components that are part of the game scene, or narrative. Providing this continuity increases player engagement which, in turn, increases learning.

A series of educational games has been designed to promote the success of engineering undergraduates in the Science, Technology, Engineering, and Mathematics (STEM) courses that are prerequisites to the undergraduate engineering curriculum. The first of these games covers pre-calculus content. The game is deployed as a desktop application and contains both two- and three-dimensional game play. Diegetic elements have been incorporated such as allowing players to manipulate an equation to align its graph with a target flight path, using a radar screen for the unit circle, and having players deliver missiles that are labeled with graphs. The second game covers calculus and physics content. This game is deployed on mobile devices. To provide a better user experience on mobile devices, all games are played in two-dimensions. Despite this additional restriction, diegetic elements have been incorporated by requiring players to draw free-body diagrams directly on in-game objects and asking players to calculate relevant parameters of missile trajectories to hit targets. The development for the final game in this series, which covers chemistry, is underway. This game will be deployed on mobile devices and incorporate chemical equations directly on game elements.

The remainder of this paper is organized as follows: First, a review of previous work on diegesis in games provides motivation for the current work. Next, the various methods used to incorporate different levels diegesis are described. Then, examples of the implementation of 
these methods in both desktop and mobile games are provided. Finally, conclusions and future work are discussed.

\section{Previous Work}

Many frequently used game design models focus on enhancing player engagement through story, or dramatic, elements [1], [2]. In games, players immersed in a compelling world are driven to be actively engaged in tasks [3]. In educational games, the combination of immersion and engagement leads to a more intense learning experience which has a positive impact on learning [4]. In practice, keeping players engaged requires implementation of diegetic elements so that the narrative of the game is not interrupted. De Freitas and Oliver expound on the importance of this by not only making diegesis one of the four dimensions of their framework for assessing educational games, but also pointing out how diegesis promotes a dual experience where players interact with the material within the game and then are provided with a natural space for reflection on learning outside of the game [5]. Prestopnik and Tang conducted an experimental study which concluded that diegesis lead to more positive perception of learning games by players [6]. It has been shown that positive perception of learning environments tend to positively affect learning outcomes [7]. There are numerous challenges in designing games for STEM education [8]. Some of these challenges can be overcome by using diegesis to increase engagement.

\section{Methodology}

It is helpful to define levels of diegesis corresponding to how well the component, or element, is integrated with the narrative and game world. Table 1 provides a summary of levels. Examples of each level are provided for entertainment and educational games. Additionally, Figure 1 and Figure 2 provide visual examples of each level in entertainment games and educational games, respectively.

Some game elements are not diegetic at all. These are usually parts of the user interface and provide information to the user. This can be desirable if they provide information the user needs often in an easily readable format. For example, consider a game where is it important for the player to know the current time. It may be frustrating for the player to always have to find a clock in the game to check the time (Figure 1(a)). In an educational game, non-diegetic elements may be used for displaying a help menu, list of reference equations, or an overview of content (Figure 2(a)). If a player is struggling and needs access to help, it is likely they have already become disengaged from the narrative due to excess difficulty [4].

Completely diegetic elements are elements that are logically placed in the game world and related to the narrative. For the entertainment game example, this could be achieved by placing a clock on a wall in the game world (Figure 1(c)). In an educational game, this would result in a question or problem that is physically represented in the game world for the player to interact with and solve. Figure 2(c) shows an example where a player must correctly load missiles by matching the graph on their flag to the function type of each air craft. 
Table 1. Levels of Diegesis.

\begin{tabular}{|l|l|l|l|}
\hline $\begin{array}{l}\text { Levels of } \\
\text { Diegesis }\end{array}$ & Description & $\begin{array}{l}\text { Example from } \\
\text { entertainment games }\end{array}$ & $\begin{array}{l}\text { Example from } \\
\text { educational games }\end{array}$ \\
\hline Non-diegetic & $\begin{array}{l}\text { An element that is } \\
\text { positioned in screen } \\
\text { space and is unrelated to } \\
\text { the narrative. }\end{array}$ & $\begin{array}{l}\text { Time information shown } \\
\text { as a plain text overlay. }\end{array}$ & $\begin{array}{l}\text { A help menu or list of } \\
\text { reference equations. }\end{array}$ \\
\hline $\begin{array}{l}\text { Moderately } \\
\text { diegetic }\end{array}$ & $\begin{array}{l}\text { An element that is } \\
\text { positioned in screen } \\
\text { space but is designed to } \\
\text { visually relate to the } \\
\text { narrative or limits } \\
\text { obstruction of the } \\
\text { player's view of the } \\
\text { game scene. }\end{array}$ & $\begin{array}{l}\text { An interactive analog } \\
\text { clock overlaid on the } \\
\text { screen. }\end{array}$ & $\begin{array}{l}\text { A question on a panel } \\
\text { that is consistent with } \\
\text { the narrative of the } \\
\text { game. }\end{array}$ \\
\hline $\begin{array}{l}\text { Completely } \\
\text { diegetic }\end{array}$ & $\begin{array}{l}\text { An element that is in } \\
\text { game space and makes } \\
\text { sense in the context of } \\
\text { the narrative. }\end{array}$ & $\begin{array}{l}\text { A clock realistically } \\
\text { positioned in the game } \\
\text { world. }\end{array}$ & $\begin{array}{l}\text { A question that is } \\
\text { physically in the game } \\
\text { space. }\end{array}$ \\
\hline
\end{tabular}

Finally, moderately diegetic elements mix some aspects of non-diegetic elements and completely diegetic elements. They usually are visually compatible with the narrative, but their location is not realistic. Alternatively, they can be positioned so they do not deter the player's ability to remain engaged. An example is placing a realistic clock on a heads-up display so that the player can easily check the time without constantly searching the game world for a clock (Figure 1(b)). In educational games, especially those involving complex mathematics, it can be difficult to convincingly place questions or problems in the real world. In that case, non-diegetic elements might be combined with diegetic elements to minimize the disruption to game play. Figure 2(b) shows an example of this where the player manipulates coefficients in a mathematical expression using a multimeter.

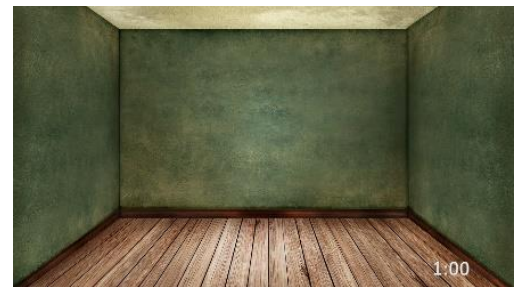

(a)

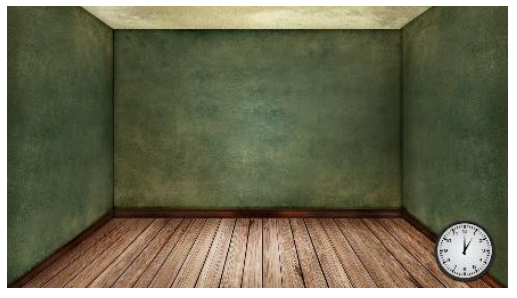

(b)

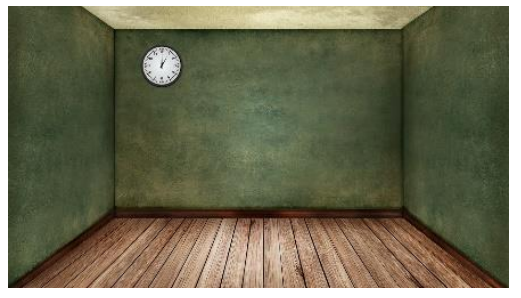

(c)

Figure 1. An example showing (a) non-diegetic, (b) moderately diegetic, and (c) completely diegetic ways to convey the current time to the player. 


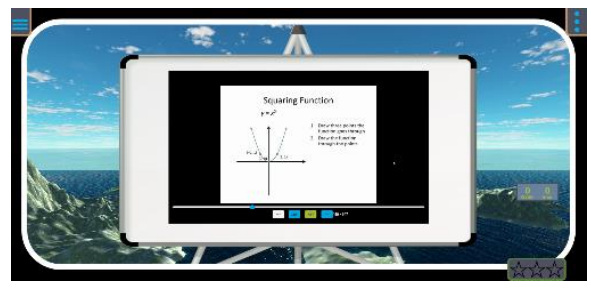

(a)

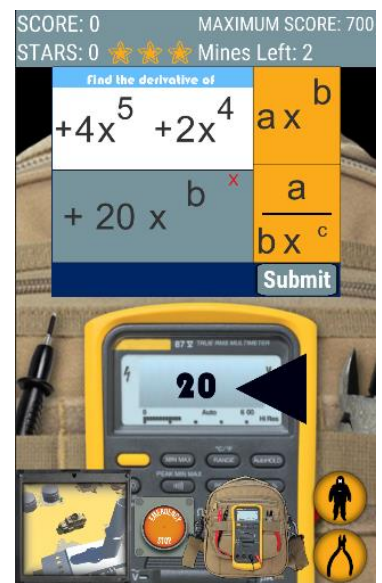

(b)

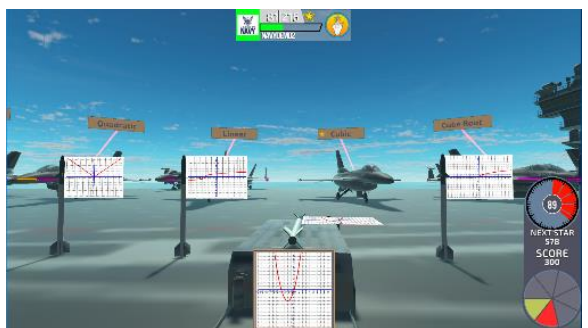

(c)

Figure 2. An example showing (a) non-diegetic, (b) moderately diegetic, and (c) completely diegetic ways to present a player with educational elements in a game.

Discussion of these levels leads to two approaches for incorporating diegesis in educational games. The first is to have goals of gameplay that are inseparable from the goals of the learning task. In this scenario, the player completes the learning task as they play the game. This is completely diegetic and the most immersive and engaging. However, especially when developing STEM educational games, there are a variety of problems that may not have goals that are easy to integrate with gameplay goals. In this case, it is necessary to combine diegetic elements with non-diegetic element to create an engaging experience. There are many methods for implementing diegesis in this way. Question panels can be designed that are partially transparent and offset so they do not obstruct the game scene. Equations and sketches can be placed on game objects. Changes made in equations or question panels can result in real-time update of objects in the game scene. If it is necessary to transition between the game scene and a learning scene, camera effects can be used to smooth this transition. All these methods will result in increased diegesis.

Choosing the right level of diegesis is an important consideration when implementing educational components. This requires balancing considerations for engagement, high quality content, and ease of player interaction. When considering which topics are best presented in games, it is prudent to consider which topics can be successful in all three of these areas. In the next section, examples of games that have been developed to meet these criteria are explored.

\section{Results and Discussion}

In this section, several examples of games where educational elements have been incorporated diegetically are presented and discussed. The discussion will focus on how these diegetic elements were implemented to increase player engagement, content quality, and ease of player interaction. Three desktop games will be presented followed by three mobile games.

\subsection{Cargo Loading}

As shown in Figure 2(c), Cargo Loading is a game in three-dimensions where the player controls a cart on the deck of an aircraft carrier. The player uses the arrow keys to drive the cart. They 
pick up missiles by driving over them and load them onto the correct plane using the mouse after they have approached the plane. Players are provided with immediate feedback on whether they have classified the function correctly as the missile disappears in a cloud of smoke when loaded incorrectly.

In this game, the game task is completely dependent on the learning task as players must classify the graphs of the function to load them correctly. As such, player engagement is completely uninterrupted throughout gameplay. The graphs on the missiles include both transformed and untransformed functions, so that the player learns to classify both. Using the arrow keys to drive the cart provides easy player interaction in a desktop application but would have to be modified for mobile deployment.

\subsection{Flight Path}

As shown in Figure 3, the Flight Path game requires the player to manipulate a flight path defined by a mathematical equation to match a target flight path. There are options to change the parent function. When this is done, the visual equation updates accordingly. As the player updates the coefficients that define the function transformation, the current flight path updates. Additionally, continuous feedback is provided using score popups which indicate how close the current path is to the target path. This is another example where the game objectives and learning objectives are inseparable which promotes player engagement. Additionally, the player clicks the up or down arrows to increase or decrease the coefficients which results in a smooth animation of the transformation. This continuity provides a powerful visualization of the mathematics content.

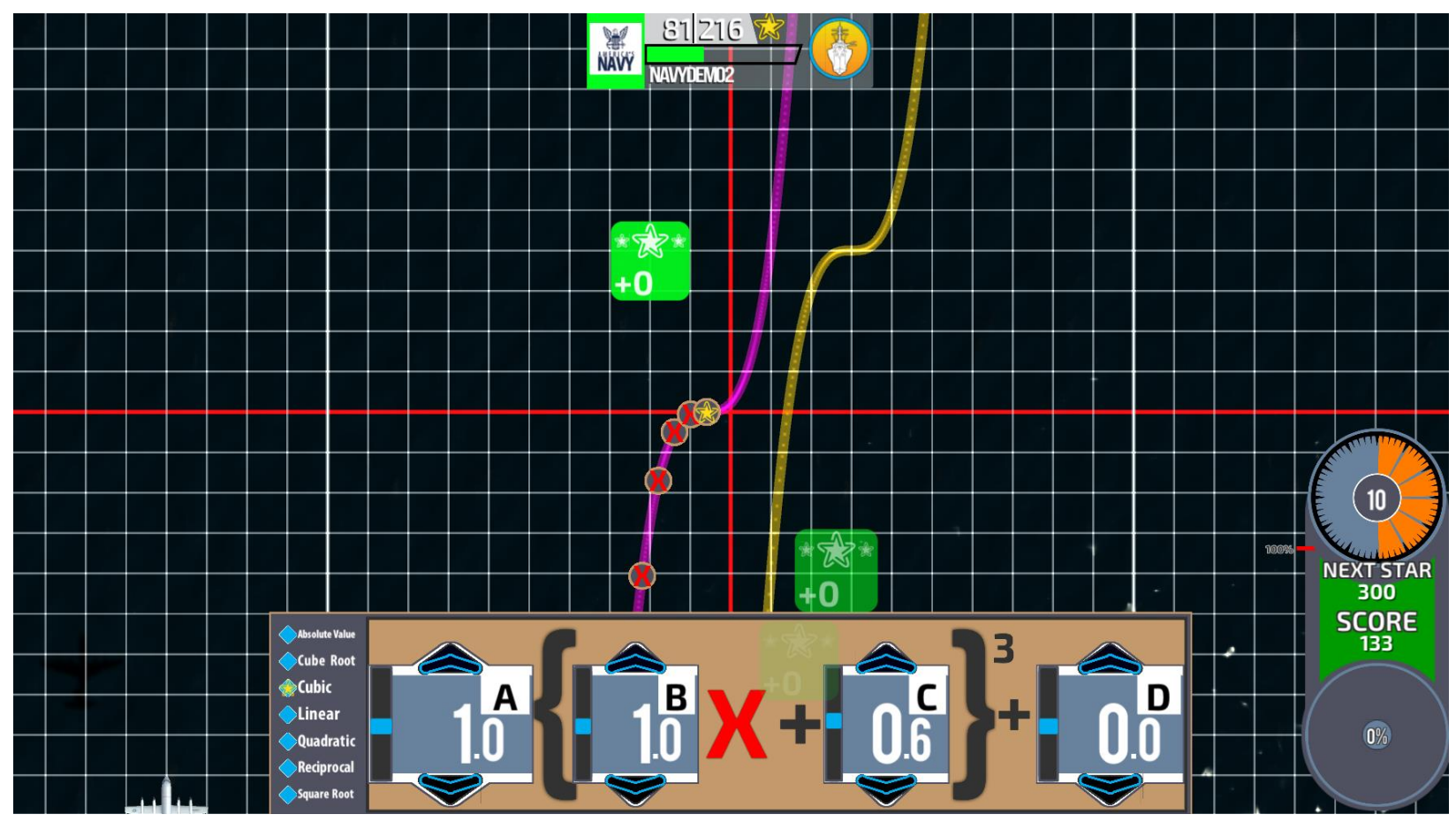

Figure 3. Flight Path game where players manipulate equations to match the current flight path to a target flight path. 


\subsection{Radar Tracking}

As shown in Figure 4, Radar Tracking is a game where the player is presented with two views of their ship. The right view is a top-down radar screen where they can see and target planes flying overhead. The left screen is a side view where they can launch retaliatory missiles to defend their ship from enemy planes. Once a plane is targeted in the radar screen, the players must answer a unit circle question correctly to earn ammunition. Then, the plane they targeted attacks their ship and they must click in the left screen to fire missile in defense. Using the same ship in both views connects the tasks in the player's mind and keeps them engaged throughout the process of targeting a plane, answering a question, and defending their ship.

In this implementation, the angle in the question is superimposed on the radar screen. The question itself is placed on a panel so that players can enter their mathematical response, but this panel is offset so that the ship and target plane remain in view. The question panel supports ease of player interaction by providing components, such as the pi symbol and fractional coefficients that can be turned on and off by clicking. This reduces the need for players to type to numeric characters. Additionally, the unit circle is a key skill in pre-calculus that helps students to understand trigonometric relationships. In this game, students are asked to convert between radians and degrees and practice evaluating trigonometric functions.

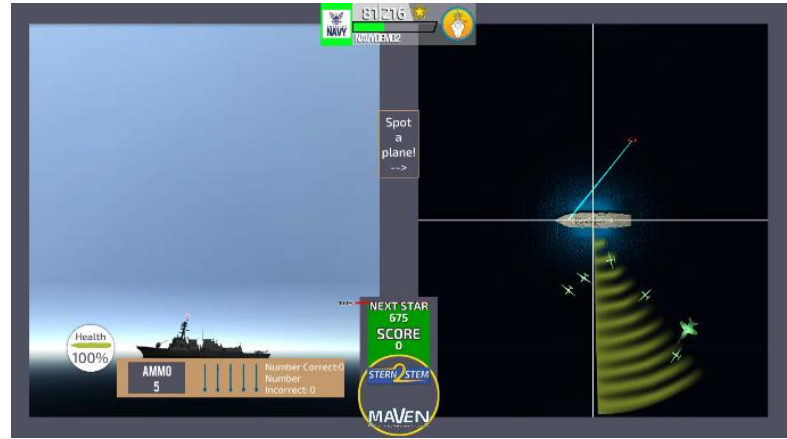

(a)

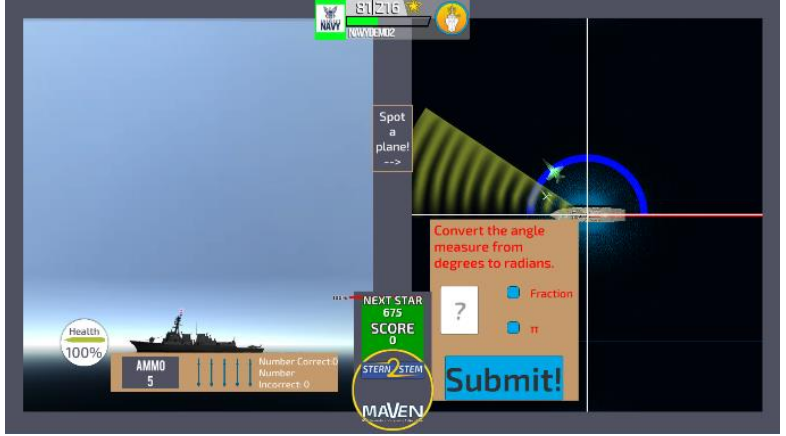

(b)

Figure 4. Radar Tracking game where players target enemy planes and then solve unit circle questions to earn ammunition to defend their ship.

\subsection{Physics Escape}

As shown in Figure 5, Physics Escape is an infinite vertical platform game where the player controls a damaged drone and tries to escape a damaged building. The player can use the onscreen joystick to move and the jump button to jump as they avoid falling debris and escape rising water. Because the drone is damaged, it hovers just above the ground and cannot fly very far vertically. Players can move the drone to interact with different physics systems in the building. When the drone gets close to one of these systems, the camera zooms in on the system and a physics problem is presented. The first step of each of these problems is to draw the freebody diagram for the system (Figure 5a). The player draws force vectors directly on the screen by dragging from the initial point to the final point of the vector. The result is checked dynamically, and the player receives feedback. In the event of a correct answer, the player is rewarded with a temporary boost in the ability to jump. Additional steps of the question are 
presented when the player interacts with the same system on higher levels. These steps require the user to solve for an unknown quantity given some properties of the system.

The diegetic design supports player engagement by using camera motions to provide continuity during the transition from the full game scene to focusing on the physics system. Making the problem full screen is necessary to facilitate player interaction. Additionally, the simple mechanics of drawing the vectors directly on the system eases the process of entering the solution. Finally since the result is checked dynamically, a variety of different systems can be easily implemented to help the player master drawing free-body diagrams which are a struggle for undergraduate engineering students and is a skill required in engineering mechanics [9].

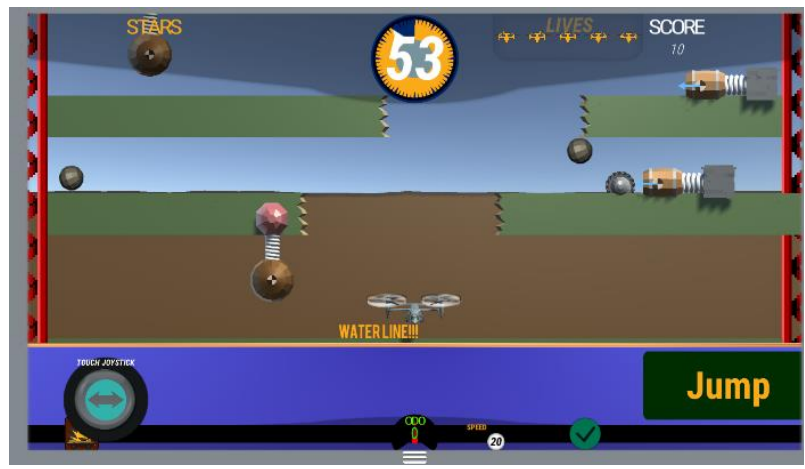

(a)

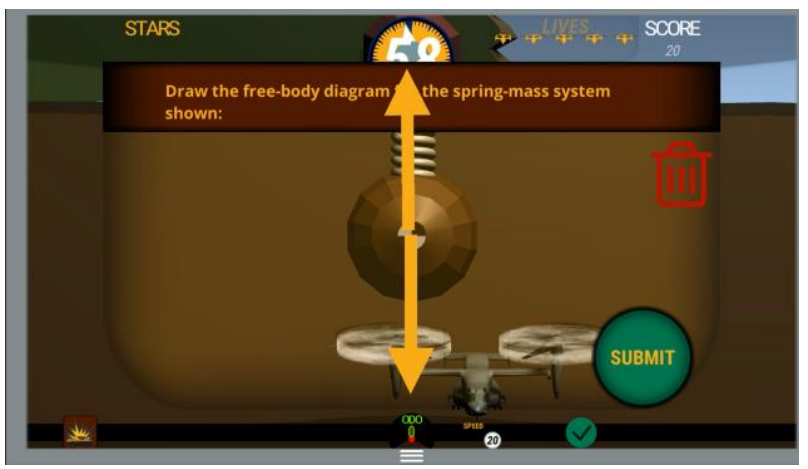

(b)

Figure 5. Physics Escape showing (a) play and (b) a player drawing a free-body diagram directly on a game object.

\subsection{Target Practice}

As shown in Figure 6, Target Practice is a game where the player is a tank that must defend against enemy rockets. To target a rocket, the player simply taps on it. Then, the player must answer a projectile motion question by calculating some information about the trajectory required to hit the rocket. The numbers in the question are computed based on the location of the rocket when the player tapped it. Therefore, the question allows the player to compute the correct missile trajectory based on the state of the game. In early levels, the trajectory is shown, and the missile moves along the path as the player adjusts the values. After clicking submit, the missile is launched. If the player's solution was correct, the enemy rocket is hit. Otherwise, the missile misses the rocket and the rocket continues undeterred.

This is an example of a game where the questions are presented directly in the game scene. The question is presented on a panel that is partially transparent balancing concerns for ease of reading with diegetic concerns. As the player interacts with the panel, the game scene updates and the final accuracy of the missile is contingent on the player answering correctly. 


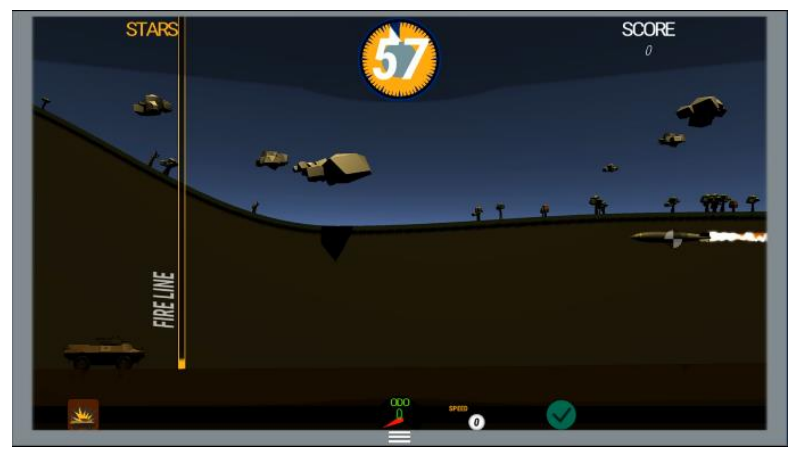

(a)

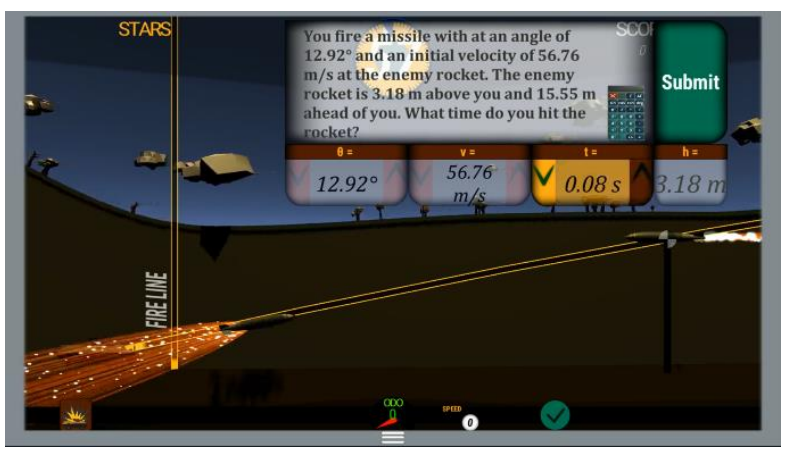

(b)

Figure 6. Target Practice showing (a) a rocket moving to strike the player and (b) the player taking aim at the rocket and calculating the trajectory required to hit the missile.

\subsection{Element Roll}

As shown in Figure 7, Element Roll is an infinite runner game where the player controls an atomic element, initially hydrogen. The player can swipe left or right to change lanes with choices of left, center, and right. Swiping up allows the atom to jump to avoid obstacles or collect powerups. Powerups are protons and neutrons which can be collected to allow the element to change isotopes or element types. Elements with more protons roll faster. If the element collides with an obstacle, atomic particles are lost which results in a loss of speed. If all atomic particles are lost, the game ends. Diegetic educational elements are implemented throughout gameplay as the number of atomic particles required to increase isotope or element type are chemically correct. Also, the atomic radius is correctly scaled.

Additionally, there are clouds of molecules involved in chemical reactions. The molecules are shown with the correct molecular shape, including geometric properties of bonds, using information from PubChem [10]. Correct visualization of elements and molecules helps players learn about the size of atoms and the structure of various molecules. These clouds cannot be avoided and when the element rolls through them, the player is presented with the corresponding chemical equation to balance as shown in Figure 8. The chemical equation is place on a rock in the game and the submit button is an asteroid. In addition, the player can still see the cloud of molecules included in the chemical reaction. A correct answer is rewarded with additional atomic particles while an incorrect answer results in the loss of atomic particles.

Since the questions are presented directly in the game world and are related to the molecules in the game, players remain engaged. The correct formatting of the chemical equations also improves the quality of the content and supports the player's ability to transfer what they have learned to coursework. 


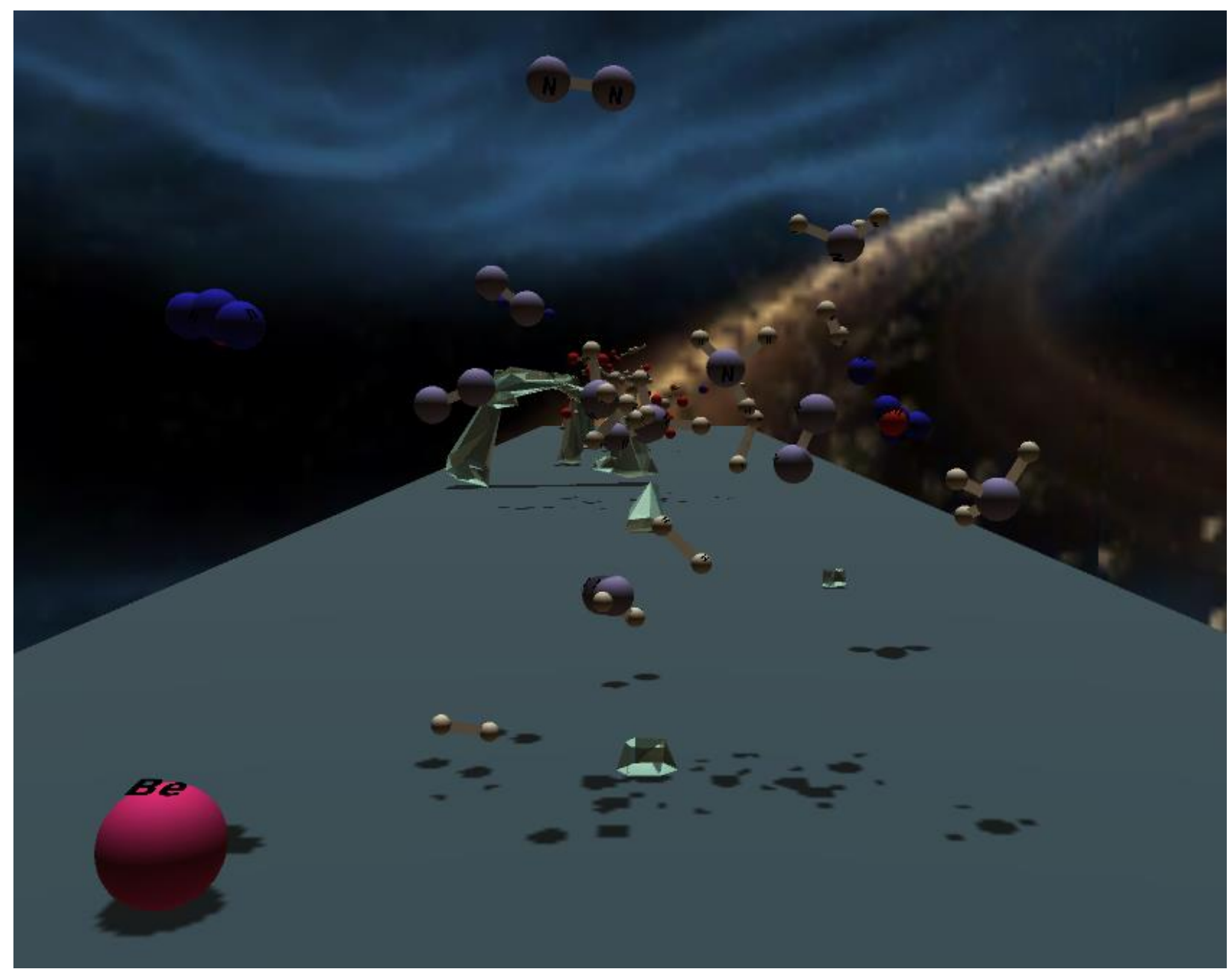

Figure 7. Element Roll during play. The player is currently beryllium. Additionally, groups of blue neutrons and red protons are visible. The cloud of molecules contains hydrogen and nitrogen which react to form ammonia.

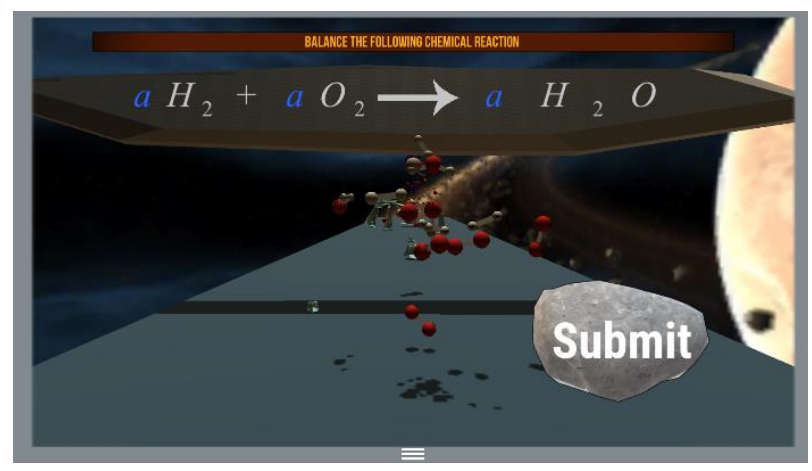

(a)

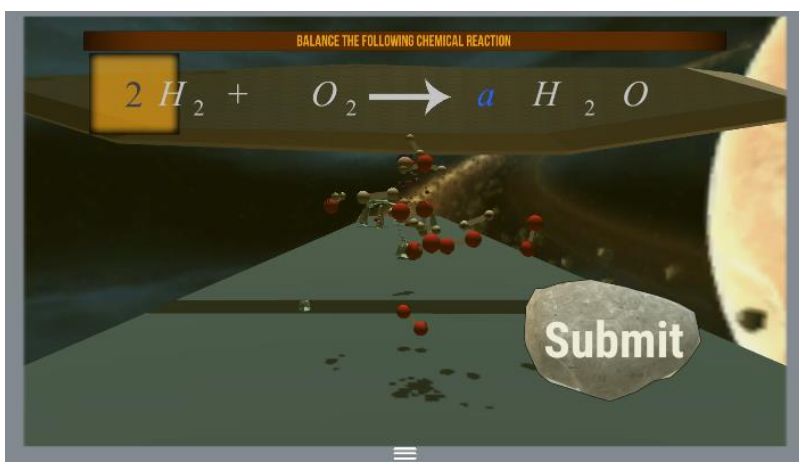

(b)

Figure 8. Element Roll after the player has been presented with a chemical equation to balance. (a) shows the initial equation and (b) shows the player editing the coefficients. 


\section{Conclusions and Future Work}

This paper has presented methods for implementing learning elements in games diegetically. Diegesis leads to increased player engagement which promotes more effective learning. The methods presented have been demonstrated in the development of a series of games for precalculus, calculus, physics, and chemistry topics at the undergraduate level. While implementing learning goals and gameplay goals that are inseparable leads to the highest level of diegesis and engagement, methods for increasing diegesis in learning elements that do not lend themselves to a completely diegetic implementation. While implementing learning elements diegetically is more complex, it is important to capitalize on one of the key benefits of educational games, i.e. games are engaging. The game developer has to ensure that the diegetic nature of the learning elements does not interfere with the quality of the content or the ease with which the player can interact with the game. Considerations should include choosing topics from the content that lend themselves to diegetic implementation in order to maximize the efficacy of the educational game.

Future work includes exploration of ways to increase engagement further by incorporating additional diegetic elements. For example, in the Element Roll game, the equation generated could not only be related to the molecules pictured, but also to the current state of the player element. In the Cargo Loading game, steps could be taken to make the flags on the missile more realistic by having them curved or waving. Special care would have to be taken to ensure that the graphs were still easy to view. Additionally, we plan to pursue further development of additional games for additional topics. It would also be very informative to conduct an efficacy study to compare the quality of learning outcomes with the level of diegesis.

Acknowledgment. This work was supported by the Office of Naval Research STEM under ONR GRANT11899718.

\section{References}

[1] J. Schell, The art of game design : a book of lenses, 2nd ed. CRC Press, 2014.

[2] T. Fullerton, Game Design Workshop. 2008.

[3] J. Y. Douglas and A. Hargadon, "The pleasures of immersion and engagement : schemas , scripts and the fifth business," Digit. Creat., 2001.

[4] C. Murphy, "Why games work - the science of learning," Modsim World 2011, 2011.

[5] S. De Freitas and M. Oliver, "How can exploratory learning with games and simulations within the curriculum be most effectively evaluated?," Comput. Educ., 2006.

[6] N. R. Prestopnik and J. Tang, "Points, stories, worlds, and diegesis: Comparing player experiences in two citizen science games," Comput. Human Behav., 2015.

[7] A. Lizzio, K. Wilson, and R. Simons, "University students' perceptions of the learning environment and academic outcomes: implications for theory and practice," Stud. High. Educ., vol. 27, no. 1, pp. 27-52, 2002.

[8] K. Smith, J. Shull, Y. Shen, A. Dean, and J. Michaeli, "Overcoming challenges in 
educational stem game design and development," in Proceedings of the 2017 Winter Simulation Conference, 2017.

[9] T. J. McCarthy and T. GoldFinch, "Teaching the concept of free body diagrams," in Proceedings of the 21st Annual Conference for the Australasian Association for Engineering Education, 2010, pp. 454-460.

[10] S. Kim, P. A. Thiessen, E. E. Bolton, J. Chen, G. Fu, A. Gindulyte, L. Han, J. He, S. He, B. A. Shoemaker, J. Wang, B. Yu, J. Zhang, and S. H. Bryant, "PubChem Substance and Compound databases.," Nucleic Acids Res., vol. 44, no. D1, pp. D1202-13, Jan. 2016. 